\title{
Neonatal Chylothorax; Spontaneous Remission: A Case Report
}

\author{
SUBIR DEY ${ }^{1}$, MA MANNAN $^{2}$, SABINA YASMIN ${ }^{3}$, NAVILA FERDOUS $^{4}$
}

\section{Introduction}

Chylothorax is a pleural collection of fluid formed by the escape of chyle from the thoracic duct or lymphatics into the thoracic cavity. ${ }^{1}$ In newborns, rapidly increased venous pressure during delivery may lead to thoracic duct rupture. Less common causes include lymphangiomatosis, restrictive pulmonary diseases, thrombosis of the duct, superior vena cava, or subclavian vein, tuberculosis or histoplasmosis, and congenital anomalies of the lymphatic system. It is the most common cause of clinically significant pleural effusion in neonates and can be congenital or acquired. Congenital chylothorax can be seen with multiple congenital malformations that result in poor development or obstruction of the lymph system. Here we report a rare case of congenital chylothorax. Chylothorax may occur as a complication of surgery or birth trauma, in association with pulmonary tumors and pulmonary lymphatic abnormalities or in association with various syndromes. However, most commonly, the etiology remains unknown and the chylothorax is considered "idiopathic". Up to $50 \%$ of all incidents of chylothorax are recognized in the first week of life, but idiopathic neonatal chylothorax may be recognized even up to several weeks of age. ${ }^{2}$ In chylothorax, the fluid triglyceride level is $>110 \mathrm{mg} / \mathrm{dL}$, the pleural fluid: serum triglyceride ratio is $>1.0$, and pleural fluid: serum cholesterol ratio is $<1.0$. Although thoracostomy drainage is the first-line therapy in the treatment of chylothorax, octreotide, a long-acting somatostatin analog that may act on somatostatin receptors in the splanchnic area to reduce lymph fluid production, has been used in chylothorax in infants and older children. ${ }^{3}$ Spontaneous recovery occurs in $>50 \%$ of cases of neonatal chylothorax. Initial therapy includes enteral

1. Registrar, Department of Neonatology, Ad-din Medical College Hospital, Dhaka.

2. Professor and Head, Department of Neonatology, Ad-din Medical College Hospital, Dhaka.

3. Assistant Professor, Department of Neonatology, Ad-din Medical College Hospital, Dhaka.

4. Registrar, Department of Neonatology, Ad-din Medical College Hospital, Dhaka.

Correspondence: Dr. Subir Dey, Registrar, Department of Neonatology, Ad-din Medical College Hospital, Dhaka. feedings with a low-fat or medium chain triglyceride, high-protein diet or parenteral nutrition. ${ }^{4}$ Thoracentesis is repeated as needed to relieve pressure symptoms. Tube thoracostomy is often performed. If there is no resolution in 1-2 wk, total parenteral nutrition is instituted.

\section{Case Report}

Baby of Farzana, a baby boy prenatally diagnosed as bilateral pleural effusion which was more prominent on right side, delivered by LUCS at $35^{+6}$ Wks gastational age with BW $2.5 \mathrm{~kg}$. The baby didn't cry soon after birth, needed full resuscitation at LDR then shifted to NICU and immediately connected to ventilator on patient triggered ventilation (PTV) mode. His initial blood gas showed $\mathrm{pH} 6.95, \mathrm{PcO}_{2} 84 \mathrm{mmHg}$, $\mathrm{Po}_{2} 45 \mathrm{mmHg}, \mathrm{BE}-13 \mathrm{mmol} / \mathrm{L}$. After sending relevant investigations treatment started with IVF, antibiotics and maintenance dose of anticonvulsants. Immediately pleural fluid was aspirated about $55 \mathrm{ml}$ from right lung which was straw in color and exudative type, pleural fluid $\mathrm{p}^{\mathrm{H}} 7.2$, serum albumin $2.31 \mathrm{gm} / \mathrm{dl}$, pleural albumin $1.55 \mathrm{gm} / \mathrm{dl}$ and ratio 0.64 ; total WBC count 1200/ $\mathrm{cmm}$, lymphocyte $90 \%$, AFB staining and culture was negative; pleural fluid LDH 1498 IU/L, serum LDH 948 $\mathrm{IU} / \mathrm{L}$ and ratio 1.5(>0.6). A few days after introducing of OG feeds, repeat chest tap was done and color of pleural fluid was changed to milky white. Repeat pleural fluid study showed pleural fluid triglyceride (TG) 473 $\mathrm{mg} / \mathrm{dl}$ and serum TG $110 \mathrm{mg} / \mathrm{dl}$ and ratio is 4.3 (>1) and pleural cholesterol $44 \mathrm{mg} / \mathrm{dl}$, serum cholesterol $104 \mathrm{mg} / \mathrm{dl}$ and the ratio is $0.42(<1)$. GeneXpert for MTB and cultures were negative. On Day 4 the baby was extubated to CPAP where he remained up to Day 11 subsequently under oxyhood and to room air (RA) on Day 17. His blood C/S was negative for any growth but CRP was as high as $44 \mathrm{mg} / \mathrm{L}$ which declined to $11 \mathrm{mg} / \mathrm{l}$. His USG of brain was found mild cerebral edema. OG feeding was started on Day 2 which was progressively increased as tolerated. Gradually clinical condition got improved and the baby feeds on demand on day 21 , voiding normally and seizure has not been observed last 2 weeks, the baby discharged on day 23 . 


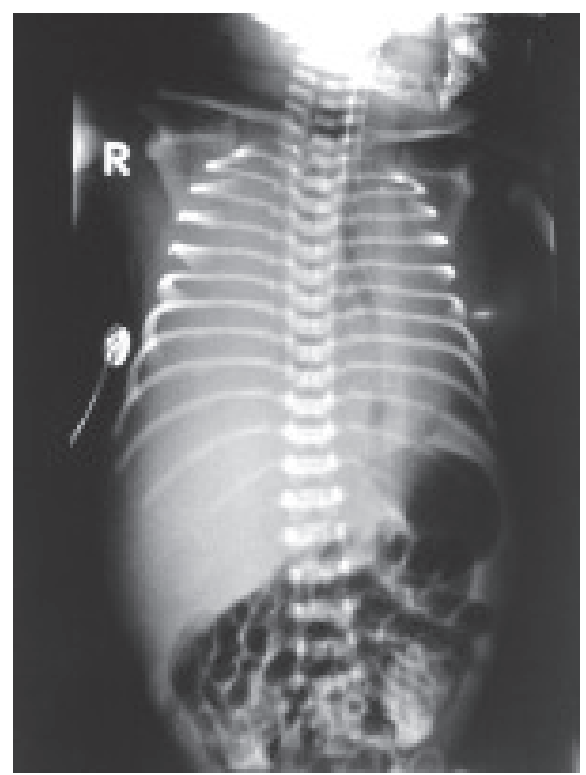

Fig. 1: Bilateral pleural effusion

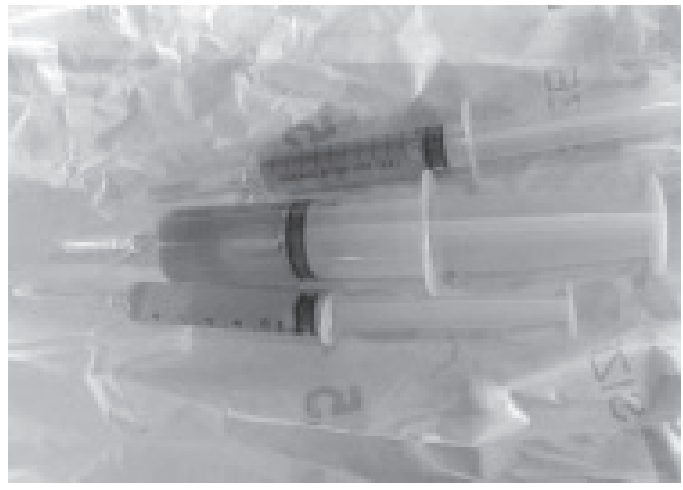

Fig. 2: Straw color pleural fluid

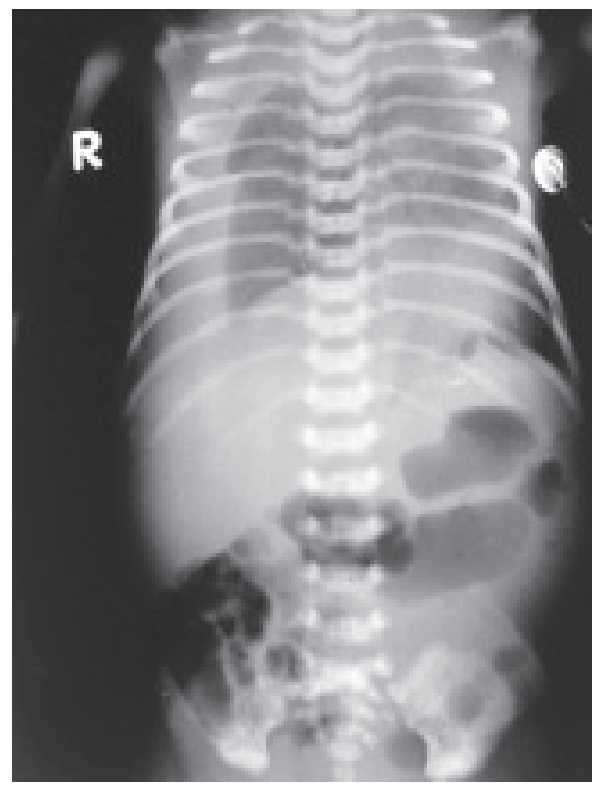

Fig. 3: Partial resolution of effusion after pleural tap

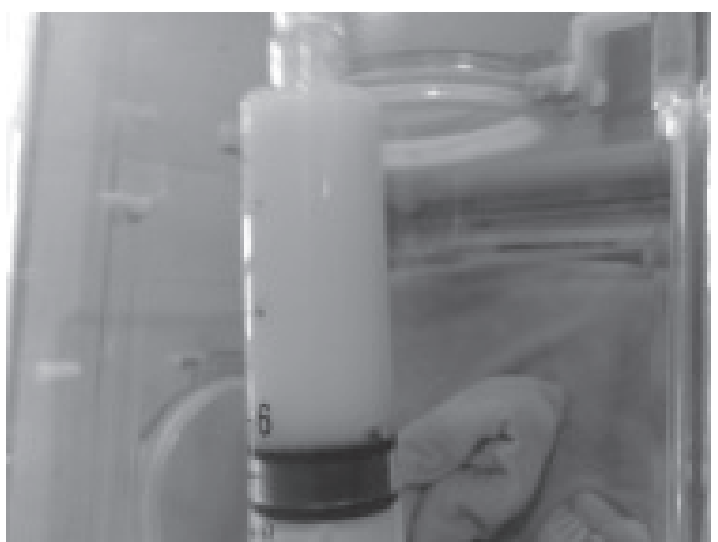

Fig. 4: Milky white pleural fluid after introduction of OG feed

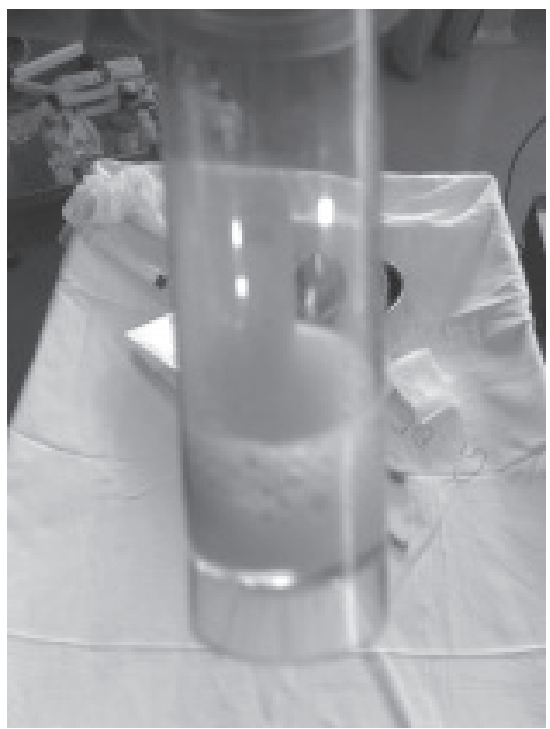

Fig. 5: Milky pleural fluid

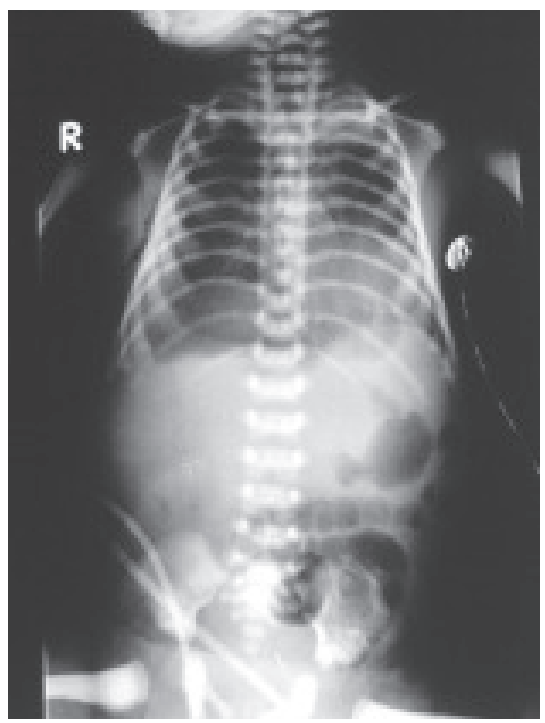

Fig. 6: Complete resolution of pleural effusion after treatment 


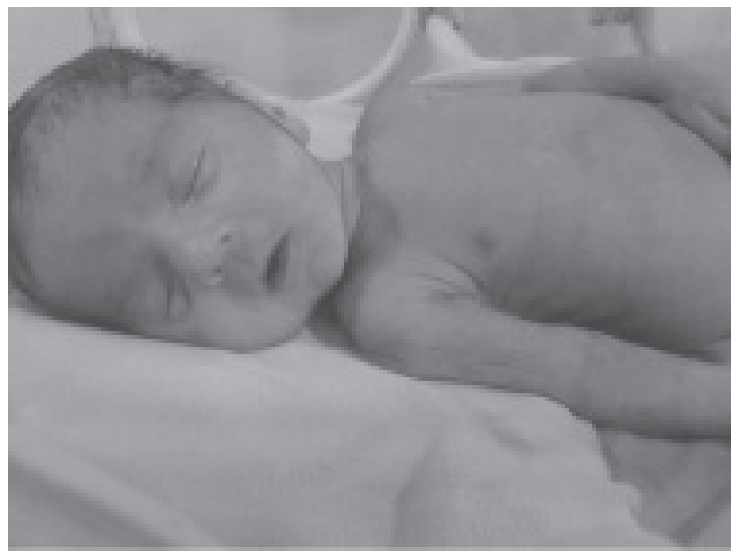

Fig. 7: Day before discharge

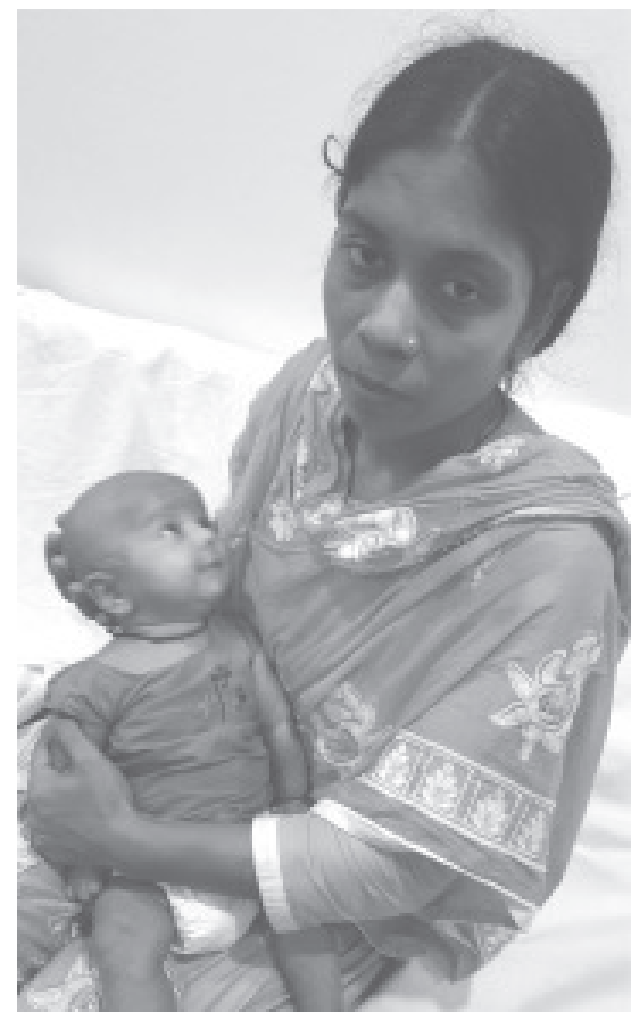

Fig. 8: F/U on Mothers lap at the age 2 months

\section{Discussion}

Etiology is unknown in the majority of neonatal chylothorax cases. Idiopathic congenital chylothorax is mostly associated with lymphangiomatosis ${ }^{5}$ congenital lymphangiectasia, ${ }^{6}$ Down's syndrome, ${ }^{7}$ and maternal polyhydramnios. ${ }^{8}$ These neonates are born with a weak thoracic duct or lymphatic anomalies. Therefore, any increase in venous pressure (e.g. during delivery) would lead to a break of the congenitally weakened thoracic duct. ${ }^{3}$ Spontaneous neonatal chylothorax is usually a transient condition that resolves by cessation of the lymphatic flow in the thorax. In the patients, dietary elimination of the long-chain fatty acids or replacement of oral feeding with total parenteral nutrition can minimize production of the lymph, and thereby decrease lymphatic flow. However, this method causes a prolongation in the duration of pleural drainage, mechanical ventilation, and total parenteral nutrition. Meanwhile, the method leads to loss of lymphocytes, proteins, coagulation factors, and antibodies as well as lymphatic fluid, and causes an increase in the occurrence of complications like hypoproteinemia, coagulopathy, lymphopenia, hypogammaglobulinemia, sepsis, and ventilator-related pulmonary injury ${ }^{9}$. In the case of continuation of drainage despite 2 to 5 weeks of total parenteral nutrition, it is advocated to perform surgery-like ligation of the thoracic ductus, pleuroperitoneal shunt, pleurectomy, or pleurosis. ${ }^{10}$

\section{References}

1. Glenna B, Winnie and Steven V. Lossef. Chylothorax: Nelson Textbook of Pediatrics: 20th ed. 2141-2.

2. Moira A. Crowley. Neonatal Respiratory Disorders. Fanar off \& Martin's Neonatal-perinatal Medicine. 10th ed. 2015.

3. Scala LG, Beghetti M, Belli D, Bugmann P, Kalangos A, Coultre CL. Etiology and management of pediatric chylothorax. J Pediatr. $2000 ; 136: 653-8$.

4. Al-Jazairi AS, Al-Zubairy SA. Octreotide as a therapeutic option for management of chylothorax. Ann Pharmacother. 2003; 37:679-82.

5. Kerr S, Goyal A, Smith NP, Jesudason EC, Losty PD. Octreotide for treatment of chylothorax after repair of congenital diaphragmatic hernia. $J$ Pediatr Surg. 2003;38:e19-e20.

6. Fitzgerald P, Canil K, Lau G. Massive chylothorax associated with lymphangiomatosis of the bone. J Pediatr Surg. 1994;29:1186-8.

7. Nishimori A, Hamamoto R, Izaki T. Drainage of subcutaneous lymphatic fluid for the management of respiratory distress in a case of generalized lymphangiectasia in an infant. Ped Surg Int. 2003;19:204-06.

8. Ergenekon E, Turan O, Canter B, Koc E, Atalay $Y$. Chylothorax and respiratory distress in a newborn with trisomy 21. Eur J Pediatr. 2001;160:744-5.

9. Brito T, Oliveira C, Sousa L. Congenital chylothorax: a case report. Ultrasound Obstet Gynecol. 2003; 21:70-1.

10. Cheung Y, Oliveira C, Leung MP, Yip M. Octreotide for treatment of postoperative chylothorax. J Pediatr. 2001;139:157-9. 